\title{
A Geometrical Approach to Reduce Calculation Times in the Definition of Rail Convoy Speed Profiles
}

\author{
MARILISA BOTTE ${ }^{1,2,}{ }^{*}$, BRUNO MONTELLA $^{2}$, LUCA D'ACIERNO $^{2}$ \\ ${ }^{1}$ Department of Agricultural Sciences \\ Federico II University of Naples \\ via Università 100, 80055 Portici (NA) \\ ITALY \\ ${ }^{2}$ Department of Civil, Architectural and Environmental Engineering \\ Federico II University of Naples \\ via Claudio 21, 80125 Naples \\ ITALY \\ *marilisa.botte@unina.it
}

\begin{abstract}
The driving speed profile definition of a rail convoy, which may be adopted as a tool in planning and operational tasks, requires the continuous verification of safety conditions. The traditional approach, based on the evaluation of the braking distance at each iteration of acceleration or cruising phases, is generally time-consuming. In this context, our proposal consists of providing a geometrical approach for obtaining the same results as the traditional approach but in lower computational times. Preliminary applications to some trial networks have shown that, although in some cases (i.e. when the speed driving profile degenerates into a triangular motion diagram) the proposed approach requires a high number of iterations, the absence of braking distance evaluations implies reductions in terms of iterations, as w ell as i $\mathrm{n}$ terms of calculation times, up to $98 \%$.
\end{abstract}

Key-Words: - rail transportation system, braking distance calculation, rail convoy movement, differential equation solution, driving speed profile, motion phases, computational time reduction

Received: July 6, 2019. Revised: January 13, 2020. Accepted: February 6, 2020.

Published: February 14, 2020.

\section{Introduction}

Railway system represents a dedicated guided transport mode in which wheel-rail adhesion conditions are dramatically lower with respect to the road conditions. Since this element, together with the peculiarity to have all trains tied to the rail tracks, implies that a faster train cannot overtake a slower one or avoid an obstacle on its route, a driver support system is required. Specifically, the set of tools and procedures aimed at ensuring safe driving conditions in railway contexts represents the so-called signalling and control system. In particular, it is based on the compliance to two paradigms: the spacing between two successive convoys and the train integrity. The first one consists in imposing a minimum distance between two successive trains so that, in the case of the first train slowing or stopping, the following one is able to react safely. The second requirement, i.e. the train integrity, consists in verifying the completeness of a train while it is operating. Basically, the signalling system transmits the movement authorities to the trains by allowing them to go ahead and with which speed value. Clearly, a speed value equal to zero represents a stop condition.
In this context, the resolution of the traction equation and the identification of different motion phases represent a key element. Typically, three different motion conditions can be identified, namely acceleration, cruising and braking phases. In some cases, especially if an energy-efficient goal is pursued, also a coasting phase is considered, in which the train moves by inertia.

Generally, micro-simulation software tools are adopted for such a purpose.

An instance of railway simulation software is RAILYSIS. It was developed by [1] and allows to simulate different operational scenarios and comparing them in terms of timetable features. In order to provide a reliable evaluation, delays are accurately modelled with related statistical distributions.

It is worth mentioning also the train movement simulator OPENTRACK ([2], [3]) which performs a mixed discrete/continuous simulation process calculating both the continuous numerical solution of the differential motion equations for the trains, by means of Euler's method [4], and the discrete processes of signal box states and delay distributions. It adopts the so-called column-graph 
and follows a hierarchical structure for the building of simulation models. Required input data concern infrastructure, signalling systems, stations, rolling stock and planned timetables.

Similar inputs are required for EGTRAIN (Environment for the design and simulaTion of RAIlway Networks) ([5], [6]) which performs a time-discrete simulation. Likewise, both simulation tools provide similar outputs: train motion diagrams (speed-distance, speed-time, distance-time trajectories); occupation times of rail sections (in both numerical and graphical format); track conflicts; statistics, such as the percentage of delayed trains at a certain station and overall train punctuality (fixing a certain delay threshold); energy consumption diagrams (electrical or mechanical power-time diagrams, electrical or mechanical energy-space diagrams).

Therefore, it is clear that the analysis of train driving profiles can be useful for several applications as, for instance, the already cited energy-saving strategies. In particular, they consist in identifying the pattern which minimises the tractive energy consumption, given a running time to be respected ([7]-[11]). Generally, for such a purpose, a coasting phase or lower speed limits are implemented. Clearly, this implies the necessity to properly take into account operational issues, both in planning and operational conditions ([12]-[20]). Moreover, also energy-recovery measures, aimed at re-using the amount of kinetic energy produced during the braking phase, could be adopted. An extensive overview of regenerative braking issues can be found in [21] and [22].

However, the most critical step in train movement is undoubtedly the braking phase, since the train has to stop in safe conditions and in a specific space distance according to the location of target points (e.g. a red signal or a station). In other words, the convoy has to know the value of speed to be adopted in each time instant to be able to halt safely. This implies the necessity of carrying out braking curves iteratively with the implementation of extremely time-consuming procedures. In this context, our work proposes a graphical method aimed at making the procedure straightforward to be performed and reducing computation times.

The remainder of the paper is organised as follows: the proposed approach is described in Section 2; it is applied to some trial rail lines in Section 3; finally, conclusions are presented in Section 4.

\section{Proposed Approach Description}

The fundamental equation, which allows to define a rail convoy movement, may be expressed by means of the following differential equation:

$$
T(v(t))-R(v(t))=\beta \cdot m \cdot \frac{d v(t)}{d t}
$$

where $v($.$) is the longitudinal travel speed of the rail$ convoy at time $t, t$ is the generical time, $T($.$) is the$ tractive effort (i.e. the tractive force) at rail wheels depending on the instantaneous speed $v(t) ; R(\cdot)$ is the sum of the longitudinal resistance to motion of the rail convoy, whose value depends on the instantaneous speed $v(t) ; \beta$ is the rotating mass coefficient expressing the ratio between the real inertia of the rail convoy (i.e. translational inertia plus inertia due to rotating masses) and the translational inertia; $m$ is the mass of the rail convoy; $d v(t) / d t$ is the first derivative of function $v(t)$.

The solution of equation (1) requires:

- the engine function definition of the considered rail convoy, expressed in terms of function $T(\cdot)$;

- the railway context definition, in terms of: slopes, curvature radii, speed limits and tunnel locations;

- the boundary condition definition, in terms of initial and final values of speed and acceleration.

In particular, with reference to the traditional four motion configurations of a rail convoy, we have to consider:

- the acceleration phase, where $T(\cdot)>R(\cdot)>0$;

- the cruising phase, where $T(\cdot)=R(\cdot)>0$;

- the coasting phase, where $T()=$.0 ;

- the deceleration phase (or braking phase), where $T(\cdot)<0$.

Typically, a train starts in a stopped condition, that is:

$$
\left\{\begin{array}{c}
t=0 \\
s(t)=0 \\
v(t)=0 \\
a(t)=d v(t) / d t=0
\end{array}\right.
$$


and it has to reach at the destination a stopped condition again, that is

$$
\left\{\begin{array}{c}
t=t^{*} \\
s\left(t^{*}\right)=L \\
v(t)=0 \\
a(t)=d v(t) / d t=0
\end{array}\right.
$$

where $s($.$) is the travel distance from the first station$ being evaluated along the curvilinear abscissa, $a(\cdot)$ is the longitudinal acceleration of the rail convoy, being expressed as the first derivative of the travel speed $v() ;$.$L is the curvilinear abscissa of the final$ station evaluated from the initial station; $t^{*}$ is the arrival time which may be defined as the time value in which the following equation is satisfied:

$$
s\left(t^{*}\right)=L
$$

Generally, the solution of the problem (1) is solved by adopting some discretisation methods, such as, for instance, the Euler's method [4].

The satisfaction of constraint (3) imposes the continuous verification of the braking distances in order to identify if the train may persevere in its motion phase (acceleration or cruising) in safe conditions or it has to start the braking phase (as shown in Fig. 1). In this context, the coasting phase may be considered as the initial period of the braking phase.

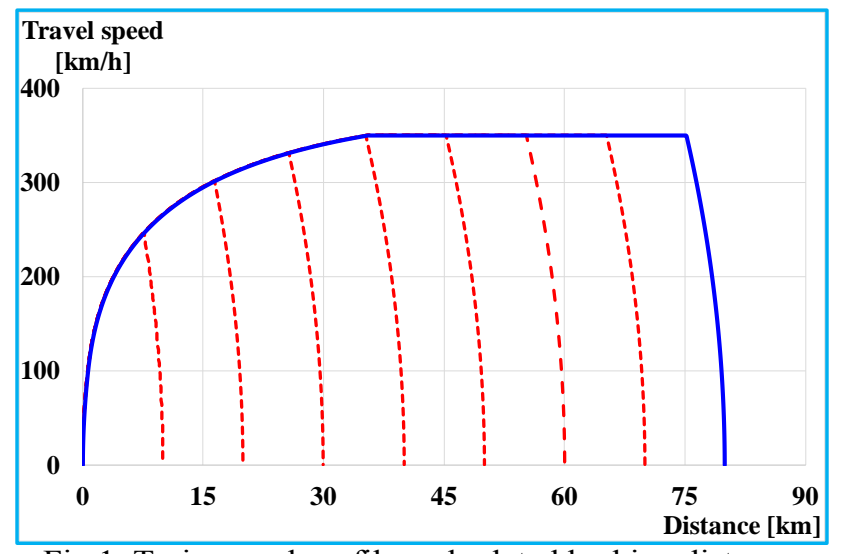

Fig.1. Train speed profile and related braking distance verifications.

Obviously, this approach is extremely timeconsuming since, at each step of the differential equation solution (the blue line in Fig. 1), it is necessary to implement a suitable subroutine (the red line in Fig. 1) which, by solving the differential equation (1), allows to calculate the braking distance.
In order to considerably reduce computational times required to solve problem (1), subject to constraints (2) and (3), we have proposed the following 4-step procedure:

1) the definition of the homogeneous track sections;

2) the definition of the initial acceleration phase;

3) the definition of the final braking phase;

4) the comparison of the speed limit intervals.

The first phase consists in dividing the train route into homogeneous space intervals where the homogeneity is evaluated with respect to the maximum travel speed. Indeed, in each track section, the maximum speed that a train can reach is the minimum value between the speed limit imposed by the signalling system and the physical maximum speed that the considered rolling stock is able to reach. In particular, as shown by Fig. 2 in the case of slope variations, for each infrastructure configuration (in terms of slope, curvature radii and tunnels), it is possible to identify a resistance curve. The intersection between the tractive effort function and the related resistance curve identifies a speed value which represents the maximum value that the considered rail convoy may reach in those conditions.

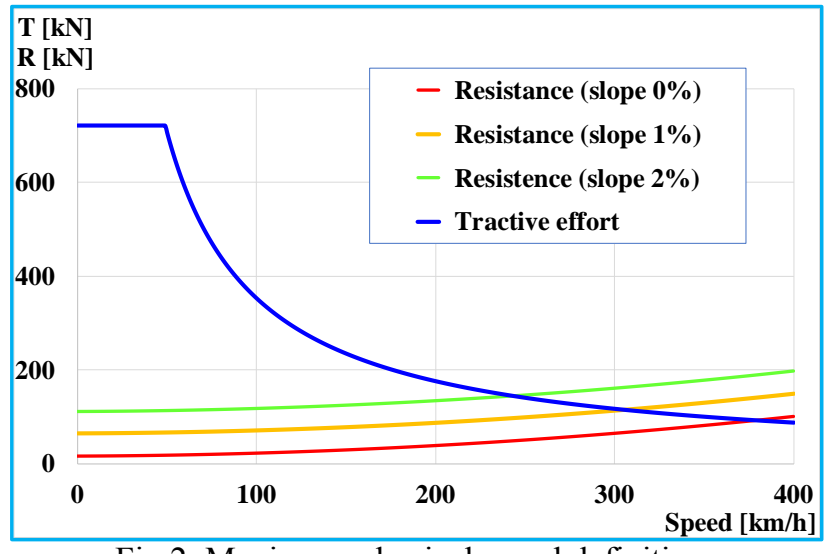

Fig.2. Maximum physical speed definition.

However, since the speed limits imposed by the signalling system, as well as the physical elements (i.e. slope, curvature radii and tunnels) determining the resistance curves, define a finite number of discrete intervals, the whole train route may be divided in a finite number of homogeneous track sections, each of them characterised by a constant maximum speed value.

The second phase consists in calculating the acceleration phase from the initial station up to the reaching of the maximum speed or the end of the 
homogeneous track section (see red lines in Fig. 3 and Fig. 4).

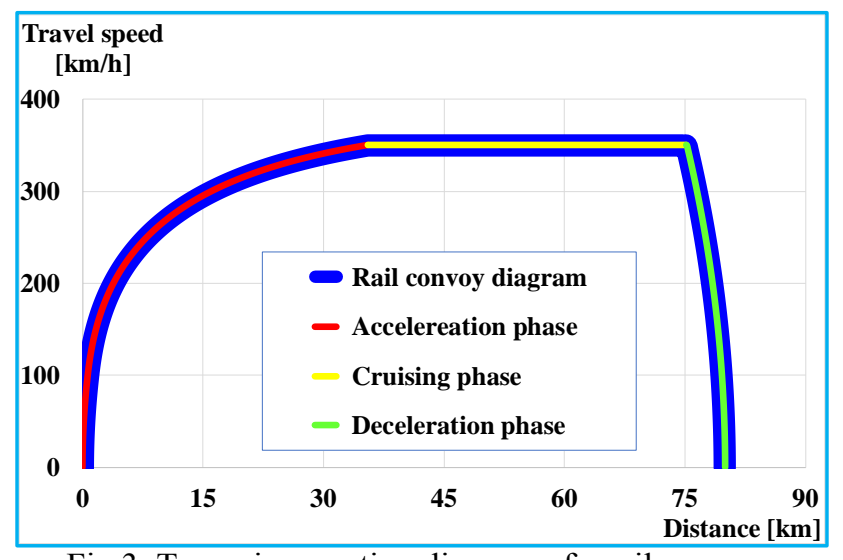

Fig.3. Trapezium motion diagram of a rail convoy.

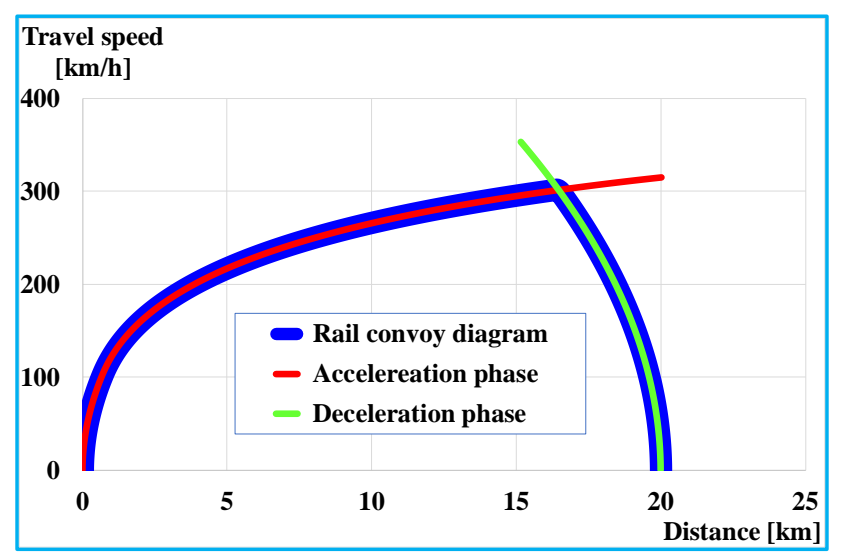

Fig.4. Triangular motion diagram of a rail convoy.

The third phase consists in applying the differential equation (1) with a backward approach, that is starting from the arrival point (i.e. the final station) and arriving at the maximum travel speed or at the initial point of the considered track section (see green lines in Fig. 3 and Fig. 4).

The final phase consists of comparing the outputs of phases 2 and 3. In particular, if both phases reach the maximum speed without covering the entire section, the remaining part is covered with a cruising phase, where the constant speed is equal to the maximum speed (see the yellow line in Fig. 3). On the contrary, if at least one of the two previous phases reach the section endpoint, it is not possible to consider a cruising phase and the motion diagram degenerates into a triangle, as shown in Fig. 4).

Similar formulations can be carried out also considering the coasting phase. In particular, since the coasting phase may be considered a w eak braking phase, it is sufficient to identify the braking phase as the combination of an initial coasting phase and a final deceleration phase.
However, the cases described in Fig. 3 and Fig. 4 are based on the assumption that there is a unique homogeneous track section. Obviously, the extension of the proposed methodology in more complex contexts (i.e. when it is possible to identify at least two homogeneous track sections) is based on the following assumption: "each track section is analysed separately and the final speed of each section represent the initial speed in the subsequent section".

The main advantage of the proposed geometrical approach consists in avoiding the continuous verification of the stopping distance by considerably reducing the calculation times.

\section{Proposed Approach Application}

In order to show the utility and the feasibility of the proposed approach, we have applied it in the case of some trial rail lines. In particular, we have considered a high-speed train 'Frecciarossa 1000' (also known as ETR 400 or ETR 1000) [23] and some trial rail lines perfectly horizontal (slope $0 \%$ ), perfectly straight (infinite curvature radius) and with the absence of tunnels. In these conditions, the maximum travel speed achievable by the considered rail convoy is equal to $383 \mathrm{~km} / \mathrm{h}$. With the assumption that a unique speed limit equal to 350 $\mathrm{km} / \mathrm{h}$ is imposed by the signalling system, the maximum speed value has to be fixed at $350 \mathrm{~km} / \mathrm{h}$.

Fig. 3 provides the motion diagram in the case of a rail line whose length is equal to $80 \mathrm{k} \mathrm{m}$. Simulation results are synthesised in Table 1 which provides a comparison between the traditional approach (based on the evaluation of the braking distance at each iteration of the acceleration or cruising phases) and the geometrical approach (based on the proposed methodology which allows to avoid the evaluation of braking distances at each iteration). In particular, the proposed approach provides a reduction equal to $98.69 \%$ in terms of iterations and equal to $98.13 \%$ in terms of calculation times.

Likewise, by considering a shorter rail line, whose extension is $20 \mathrm{k} \mathrm{m}$, we obtain the motion diagram shown in Fig. 4. Simulation results, shown in Table 2, highlight the positive performance of the geometrical approach which achieves a r eduction equal to $97.44 \%$ in terms of iterations and equal to $95.01 \%$ in terms of calculation times.

Finally, we have analysed a more complex case consisting in an $80-\mathrm{km}$ rail line with 4 different speed limits $(350 \mathrm{~km} / \mathrm{h}, 300 \mathrm{~km} / \mathrm{h}, 250 \mathrm{~km} / \mathrm{h}$ and $200 \mathrm{~km} / \mathrm{h}$ ). Details of the simulation results are described in terms of the motion diagram in Fig. 5 
and in terms of algorithm performance in Table 3. In this case, numerical results show that the geometrical approach is able to provide a reduction equal to $98.37 \%$ in terms of iterations and equal to $97.83 \%$ in terms of calculation times.

Table 1. Simulation results in the case of a unique track section $80 \mathrm{~km}$ long

\begin{tabular}{|c|c|c|c|c|c|c|c|}
\hline \multirow[b]{2}{*}{ Approach } & \multicolumn{3}{|c|}{$\begin{array}{l}\text { Number of iterations } \\
\text { (motion phases) }\end{array}$} & \multicolumn{2}{|c|}{$\begin{array}{c}\text { Number of iterations } \\
\text { (braking distance evaluation) }\end{array}$} & \multirow{2}{*}{$\begin{array}{c}\text { Total } \\
\text { number } \\
\text { of } \\
\text { iterations }\end{array}$} & \multirow{2}{*}{$\begin{array}{c}\text { Total } \\
\text { calculation } \\
\text { time } \\
\text { [sec] }\end{array}$} \\
\hline & $\begin{array}{l}\text { Acceleration } \\
\text { phase }\end{array}$ & $\begin{array}{l}\text { Cruising } \\
\text { phase }\end{array}$ & $\begin{array}{l}\text { Braking } \\
\text { phase }\end{array}$ & $\begin{array}{c}\text { During } \\
\text { acceleration } \\
\text { phase }\end{array}$ & $\begin{array}{l}\text { During } \\
\text { cruising } \\
\text { phase }\end{array}$ & & \\
\hline $\begin{array}{c}\text { Traditional } \\
\text { (with braking } \\
\text { distance } \\
\text { evaluation) } \\
\end{array}$ & 503 & 408 & 98 & 35,781 & 39,984 & 76,774 & 76.20 \\
\hline $\begin{array}{c}\text { Geometrical } \\
\text { (without braking } \\
\text { distance } \\
\text { evaluation) }\end{array}$ & 503 & 408 & 98 & $\begin{array}{c}\text { not } \\
\text { applicable }\end{array}$ & $\begin{array}{c}\text { not } \\
\text { applicable }\end{array}$ & 1,009 & 1.42 \\
\hline
\end{tabular}

Table 2. Simulation results in the case of a unique track section $20 \mathrm{~km}$ long

\begin{tabular}{|c|c|c|c|c|c|c|c|}
\hline \multirow[b]{2}{*}{ Approach } & \multicolumn{3}{|c|}{$\begin{array}{c}\text { Number of iterations } \\
\text { (motion phases) }\end{array}$} & \multicolumn{2}{|c|}{$\begin{array}{c}\text { Number of iterations } \\
\text { (braking distance evaluation) }\end{array}$} & \multirow{2}{*}{$\begin{array}{l}\text { Total } \\
\text { number } \\
\text { of } \\
\text { iterations }\end{array}$} & \multirow{2}{*}{$\begin{array}{c}\text { Total } \\
\text { calculation } \\
\text { time } \\
{[\mathrm{sec}]}\end{array}$} \\
\hline & $\begin{array}{l}\text { Acceleration } \\
\text { phase }\end{array}$ & $\begin{array}{c}\text { Cruising } \\
\text { phase }\end{array}$ & $\begin{array}{c}\text { Braking } \\
\text { phase }\end{array}$ & $\begin{array}{c}\text { During } \\
\text { acceleration } \\
\text { phase }\end{array}$ & $\begin{array}{c}\text { During } \\
\text { cruising } \\
\text { phase }\end{array}$ & & \\
\hline $\begin{array}{c}\text { Traditional } \\
\text { (with braking } \\
\text { distance } \\
\text { evaluation) } \\
\end{array}$ & 294 & 0 & 84 & 16,549 & 0 & 16,927 & 17.13 \\
\hline $\begin{array}{c}\text { Geometrical } \\
\text { (without braking } \\
\text { distance } \\
\text { evaluation) }\end{array}$ & 336 & 0 & 98 & $\begin{array}{c}\text { not } \\
\text { applicable }\end{array}$ & $\begin{array}{c}\text { not } \\
\text { applicable }\end{array}$ & 434 & 0.85 \\
\hline
\end{tabular}

Table 3. Simulation results in the case of multiple track sections $80 \mathrm{~km}$ long

\begin{tabular}{|c|c|c|c|c|c|c|c|}
\hline \multirow[b]{2}{*}{ Approach } & \multicolumn{3}{|c|}{$\begin{array}{c}\text { Number of iterations } \\
\text { (motion phases) }\end{array}$} & \multicolumn{2}{|c|}{$\begin{array}{c}\text { Number of iterations } \\
\text { (braking distance evaluation) }\end{array}$} & \multirow{2}{*}{$\begin{array}{c}\text { Total } \\
\text { number } \\
\text { of } \\
\text { iterations }\end{array}$} & \multirow{2}{*}{$\begin{array}{c}\text { Total } \\
\text { calculation } \\
\text { time } \\
{[\mathrm{sec}]}\end{array}$} \\
\hline & $\begin{array}{l}\text { Acceleration } \\
\text { phase }\end{array}$ & $\begin{array}{l}\text { Cruising } \\
\text { phase }\end{array}$ & $\begin{array}{l}\text { Braking } \\
\text { phase }\end{array}$ & $\begin{array}{c}\text { During } \\
\text { acceleration } \\
\text { phase }\end{array}$ & $\begin{array}{l}\text { During } \\
\text { cruising } \\
\text { phase }\end{array}$ & & \\
\hline $\begin{array}{c}\text { Traditional } \\
\text { (with braking } \\
\text { distance } \\
\text { evaluation) } \\
\end{array}$ & 331 & 836 & 88 & 19,730 & 57,064 & 78,049 & 77.46 \\
\hline $\begin{array}{c}\text { Geometrical } \\
\text { (without braking } \\
\text { distance } \\
\text { evaluation) } \\
\end{array}$ & 336 & 836 & 98 & $\begin{array}{c}\text { not } \\
\text { applicable }\end{array}$ & $\begin{array}{c}\text { not } \\
\text { applicable }\end{array}$ & 1,270 & 1.68 \\
\hline
\end{tabular}

A relevant aspect emerging from the data analysis is that the use of the geometric approach, in the cases where there are triangular motion diagrams (i.e. $20-\mathrm{km}$ line and in the first section of the 4-speed-limit intervals), provides a greater number of iterations for the evaluation of the acceleration and braking phases (the surplus is related to the overlapping parts) compared to the traditional approach. However, the absence of braking distance evaluations compensates for this increase, both in terms of iteration and calculation times. 


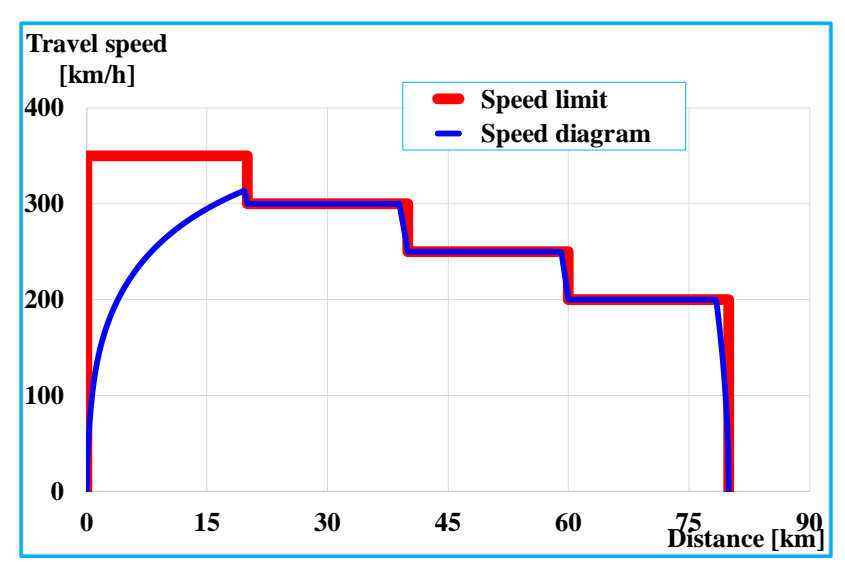

Fig.5. Speed limits and train speed profile.

\section{Conclusions}

The definition of speed driving profiles represents a relevant tool in the planning and operational tasks of railway systems. The main limitation in the application development is the high calculation times required to mimic the real behaviour of rail convoys. Indeed, similarly to driving assistance systems, it is necessary to implement continuously, at each instant of an acceleration or cruising phase, a safe procedure consisting in calculating (by means of a differential equation solution) the braking distance and in verifying if the current motion condition may be preserved or the train has to start the braking phase.

Our proposal consists in dividing the train route into different homogeneous track sections where it is possible to identify a unique maximum speed value (i.e. the minimum between the speed limit imposed by the signalling system and the maximum physical speed determined as a function of the rail convoy performance and the track section features) that may be achieved by the analysed rail convoy. In each track section, the acceleration and the breaking phases are calculated once and a geometrical comparison allows to determine the transition point (in the case of triangular motion diagram), as well as the portion of cruising phase (in the case of trapezium motion diagram). In both cases, the absence of a time-consuming routine, such as the braking distance verification, allows to considerably reduce computational times.

As research prospect, we suggest to apply the proposed geometrical methodology for determining optimal speed profiles in order to implement energy-saving strategies, as $\mathrm{w}$ ell as other operational tasks.

\section{References:}

[1] Radtke A, Bendfeldt J, Handling of railway operation problems with RailSys, Proceedings of the 5th World Congress on Rail Research WCRR 2001, Cologne, Germany, 2001.

[2] Huerlimann D, Objektorientierte Modellierung von Infrastrukturelementen und Betriebsvorgängen im Eisenbahnwesen. Ph.D. dissertation, University ETH Zürich, Switzerland, 2001.

[3] Nash A, Huerlimann D, Railroad simulation using OpenTrack, WIT Transaction on the Built Environment,Vol.74, 2004, pp. 45-54.

[4] Butcher JC, The numerical analysis of ordinary differential equations: Runge-Kutta and general linear methods, Wiley Interscience, New York (NY), USA, 1987.

[5] Quaglietta E, (2011) A Microscopic Simulation Model for supporting the design of railway systems: development and applications. Ph.D. dissertation, University of Naples Federico II, Italy, 2011.

[6] Quaglietta E, Punzo V, Supporting the design of railway systems by means of a $\mathrm{S}$ obol variance-based sensitivity analysis. Transportation Research Part C, Vol.34, 2013, pp. 38-54.

[7] Miyatake M, Ko H, Optimization of train speed profile for minimum energy consumption. IEEJ Transactions on Electrical and Electronic Engineering, Vol.5, 2010, pp. 263-269, 2010.

[8] Albrecht A, Howlett P, Pudney P, Vu X, Energy-efficient train control: from local convexity to global optimization and uniqueness. Automatica, Vol.49, 2013, pp. 3072-3078.

[9] De Martinis V, Gallo M, D'Acierno L, Estimating the benefits of energy-efficient train driving strategies: a model calibration with real data. WIT Transactions on the Built Environment, Vol.130, 2013, pp. 201-211.

[10] De Martinis V, Weidmann U, Gallo M, Towards a simulation-based framework for evaluating energy-efficient solutions in train operation. WIT Transactions on the Built Environment, Vol.135, 2014, pp. 721-732.

[11] Botte M, D'Acierno L, Dispatching and rescheduling tasks and their interactions with travel demand and the energy domain: Models and algorithms. Urban Rail Transit, Vol.4, 2018, pp. 163-197.

[12] Botte M, D'Acierno L, Montella B, Placido A, A stochastic approach for assessing intervention strategies in the case of metro system failures. Proceedings of the 2015 AEIT 
International Annual Conference, Naples, Italy, 2015.

[13] Gallo M, D'Acierno L, Montella B, A multimodal approach to bus frequency design. WIT Transactions on the Built Environment, Vol.116, 2011, pp.193-204.

[14] Botte M, Di Salvo C, Caropreso C, Montella B, D'Acierno L, Defining economic and environmental feasibility thresholds in the case of rail signalling systems based on satellite technology. Proceedings of the 16th IEEE International Conference on Environment and Electrical Engineering (IEEE EEEIC 2016), Florence, Italy, 2016.

[15] Botte M, Di Salvo C, Placido A, Montella B, D'Acierno L, A Neighbourhood Search Algorithm for determining optimal intervention strategies in the case of metro system failures. International Journal of Transport Development and Integration, Vol.1, 2017, pp. 63-73.

[16] Caropreso C, Di Salvo C, Botte M, D'Acierno L, A long-term analysis of passenger flows on a regional rail line. International Journal of Transport Development and Integration, Vol.1, 2017, pp. 329-338.

[17] Di Mauro R, Botte M, D’Acierno L, An analytical methodology for extending passenger counts in a metro system. International Journal of Transport Development and Integration, Vol.1, 2017, pp. 589-600.

[18] Placido A, Petito C, Gallo M, D'Acierno L, Managing disruptions and disturbances on railway services: A real-scale case study. International Journal of Transport Development and Integration, Vol.1, 2017, pp. 695-710.

[19] D'Acierno L, Botte M, Pignatiello G, A simulation-based approach for estimating railway capacity. International Journal of Transport Development and Integration, Vol.3, 2019, pp. 232-244.

[20] Alfieri L, Botte M, D'Acierno L, Pagano M, Effects of urban metro energy-saving strategy on the distribution electrical power system. Proceedings of the 2019 IEEE Vehicle Power and Propulsion Conference (IEEE VPPC 2019), Hanoi, Vietnam, 2019.

[21] Gonzalez-Gil A, Palacin R, Batty P, Sustainable urban rail systems: Strategies and technologies for optimal management of regenerative braking energy. Energy
Conversion and Management, Vol.75, 2013, pp. 374-388.

[22] Ghavihaa N, Campilloa J, Bohlinb M, Dahlquista $\mathrm{E}$, Review of application of energy storage devices in railway transportation. Energy Procedia, Vol.105, 2017, pp. 4561-4568.

[23] Wikipedia, $\quad 1000$. https://en.wikipedia.org/wiki/Frecciarossa_100 0 (last access: February 2020). 